\title{
Effect of Size Selection Within and Between Fishing Gear Types on the Yield and Spawning Stock Biomass Per Recruit and Yield Per Unit Effort for a Cohort of an Idealized Groundfish
}

\author{
Joseph DeAlteris and Ralf Riedel \\ University of Rhode Island \\ Department of Fisheries, Animal and Veterinary Science \\ Kingston, R. I. 02881, USA
}

\begin{abstract}
A discrete time model was developed to evaluate yield and spawning stock biomassper-recruit and yield-per-unit-effort for a cohort of an idealized groundfish. This fish was characterized as relatively long lived $(M=0.2)$, slow growing $(K=0.2)$, with maximum length and weight of $100 \mathrm{~cm}$ and $10 \mathrm{~kg}$, respectively, and $50 \%$ maturity at a relatively early age of 3 years. The size selection characteristics of trawls and hooks were described by a logistic cumulative distribution function (LCDF) with a range of $L_{50}$ and steepness values. The size selection characteristics of gillnets and traps were described by a scaled normal probability density function (NPDF) with a range of values for $\mathrm{L}_{\text {opt }}$ and the standard deviation.
\end{abstract}

Analysis of isopleth diagrams for yield-per-recruit (YPR) and spawning stock biomassper-recruit (SPR) for both types of selection functions indicated that YPR is maximized when harvesting is directed on a fish length slightly larger than that at which biomass for the cohort of the unfished population is maximized, and at fishing mortality rates of 2 and greater. Under these harvesting conditions, SPR was between 24 and $36 \%$ of the unfished condition. At these levels of fishing mortality and $L_{50}$, the steepness of the LCDF does not affect the cohort YPR, but does significantly affect the SPR. Likewise, at these levels of fishing mortality and $L_{\text {opt }}$, the standard deviation of the NPDF also does not affect the cohort YPR, but does significantly affect the SPR. Thus, a sharper selection process provides a greater SPR available for production of future cohorts.

In contrast, yield-per-recruit-per-unit-effort (YPRPUE) is maximized at fishing mortality values of approximately 0.5 , when the age at entry or length of susceptibility to fishing gear is set at the age or length of maximum biomass for the unfished cohort.

These results present a dilemma for the fishery resource manager: maximize cohort YPR at fishing mortality values of 2 and greater, with a minimum $65 \%$ reduction in YPRPUE, or maximize YPRPUE with a $25 \%$ reduction in YPR. However, with compromise, $85 \%$ of the maximum YPR can be realized with only a $20 \%$ reduction of YPRPUE at a fishing mortality level of 0.75

Key words: $\quad$ Fishing gear, gear selectivity, groundfish

\section{Introduction}

\section{Statement of the Problem and Objective}

In the last three decades, considerable progress has been made in defining the selection characteristics of various fish harvesting gears. Fishery managers and fishing gear technologists have investigated the subtle characteristics of species-specific size selection as a function of mesh size and shape in trawls, mesh size and hanging ratio in gillnets, hook size and style in longlines, and mesh size and funnel opening size in traps, so as to provide improved management of fishery stocks harvested with these gear types. In contrast, models of yield-per-recruit (YPR) and spawning stock biomass-per-recruit (SPR) used in the analysis of fish population dynamics have sometimes assumed knife-edge selection at a single length or age. The purpose of the present research, therefore, was to integrate gear-specific size selection into YPR and SPR models. The development of a generalized model applied to a hypothetical or "idealized" groundfish is the prelude to the application of the model to specific Northwest Atlantic groundfish species using selectivity data for harvesting gear, either presently used in the fisheries or proposed for future use. 


\section{Literature Review}

The YPR models are useful to fishery resource managers for predicting the effects of alterations in harvesting activity on the yield available from a given year-class or cohort (Gulland, 1983). Given everything else, two elements that define the model and are usually regulated by resource managers are: fishing mortality $(F)$ and the pattern of harvesting activity on different sizes of fish. Often the latter element has been simplified by assuming knife-edge selection (100\% vulnerability at age of first capture), so that the Beverton and Holt (1957) analytical solution to the yield equation could be applied (Gulland, 1969 and 1983; Pauley, 1984; Ricker, 1975; Saila et al., 1988; Sparre et al., 1989). While this assumption may be appropriate for size selection that follows a logistic distribution function, as is sometimes observed in a trawl codend, the Beverton-Holt yield equation does not incorporate recent advances in understanding the size selection processes of the principal gear types used on groundfish (trawls, traps, gillnets and longlines).

The study of size selection characteristics of fish harvesting gear began in the early-1900s with an application toward fishery management (Baranov, 1918). In the late-1950s, the International Commission for the Northwest Atlantic Fisheries (ICNAF) co-sponsored a special scientific meeting on the selectivity of fishing gear (Anonymous, 1963), and research summarized in the proceedings of that meeting were the basis for three decades of progress. The size selectivity of all fish harvesting gear can be classified broadly into two types of probability distributions (Clark, 1960; Holt, 1963; Pope et al., 1975):

1. A sigmoid curve, increasing from some positive value less than 1 to 1 as a function of fish size. This curve is represented by a logistic cumulative distribution function (LCDF). The selection characteristics of this curve are, that all fish smaller than a particular size $\left(L_{1}\right)$ are not captured $(P=0)$, that all fish larger than a particular size $\left(L_{2}\right)$ are captured $(P=1)$; and that fish of a certain size $\left(L_{50}\right)$ between $L_{1}$ and $L_{2}$ have a $50 \%$ probability of capture $(P=0.5)$ if encountering the gear.

2. A dome-shaped curve, increasing from some positive value less than 1 to 1 , then decreasing again as a function of fish size. This curve is represented by a truncated, rescaled normal probability density function (NPDF). The characteristics of this curve are that all fish smaller than a particular size $\left(L_{1}\right)$ and larger than another particular $\left(L_{2}\right)$ are not captured, and that fish of a certain size $\left(L_{\text {opt }}\right)$ between $L_{1}$ and $L_{2}$ have a $100 \%$ probability $(P=1.0)$ of capture if encountering the gear.
Groundfish size selection by a trawl codend may be modeled by a LDCF. Early work by Clark (1963) estimated sigmoid selection curves for groundfish species in the Northwest Atlantic. In the 1970s and 1980s additional research provided species - and mesh size-specific selection curves (Smolowitz, 1983). More recent work has attempted to further define codend selectivity as a function of mesh shapes, (square versus diamond) and to relate mesh shape to codend escape survival (DeAlteris and Reifsteck, 1993). For groundfish selection by trawl codends, the following generalizations may be made: 1) larger meshes retain fewer small fish, shifting the selection curve to the right; 2) square mesh codends steepen the selection curve and shift it slightly to the right, as compared to a codend of similar mesh size of diamond shape.

Groundfish size selection by a gillnet may sometimes be modeled by a NPDF (Hamley, 1975). Early work by Regier and Robson (1966) established an experimental methodology to describe the parameters of a normal distribution used to characterize the selectivity of the gillnet. Later work by Borgstrom (1989), and Hamley and Regier (1973) further defined the application of the NPDF distribution function to gillnet selection. More recently, Lazar and DeAlteris (1993), presenting the results of an analysis of gillnet selection in the Gulf of Maine groundfish fishery, used a truncated twoterm Gram Charlier series model to define in greater detail the shape of the selection curve.

Groundfish size selection by a longline with hooks may be modeled by a sigmoid curve (McCracken, 1963 and Sætersdal, 1963). However, more recent work on hook selectivity is equivocal. Ralston (1982), investigating the Hawaiian deep-sea handline fishery, concluded that a sigmoid curve most accurately described the selective properties of the gear in that fishery. Similar results were reported by Bertrand (1988) in his analysis of hook selectivity in the handline fishery of the Saya de Malha Banks (Indian Ocean). In contrast, Ralston (1990), investigating the size selection of snappers by hook and line gear, concluded that neither model in its simplest form depicted hook selectivity. Similarly, Otway and Craig (1993) studied the effects of hook size in catches of undersize snapper and also determined that neither the normal nor the logistic model was appropriate.

Groundfish size selection by traps has not been investigated previously, so selectivity must be inferred from the few trap selection experiments conducted in other fisheries. Stevenson and StuartSharkey (1980) tested the effect of three different mesh sizes and found that increasing the mesh size led to a significant reduction in the number of 
smaller fish caught. Ward (1988), reporting on the results of mesh size experiments in the Bermuda trap fisheries, developed sigmoid-shape selection curves for the dominant species. However, as noted by Ward, since the traps had very large funnel openings relative to the maximum fish size in the population, nothing prevented entry by even the largest fish. Bohnsack et al. (1989) investigated the effect of fish trap mesh size on reef fish off southeastern Florida and found that larger meshes retained fewer small fish. It is clear that the mesh covering a trap will affect the retention of the smaller fish. If there is no restriction to entry by the largest fish in the population, the selection curve may be sigmoid. However, the traps with the highest catch efficiency will have funnel openings small enough so as to impede the exit of captured fish that would otherwise be retained by the mesh size. Therefore these traps may have a dome-shaped selection curve.

\section{Methods}

A discrete time model was developed using a computer based spreadsheet. The time step was set at 0.1 years, over the range of 0 to 30 years.

The length of the fish ( $L$ ) at age (t) was calculated using a simplified $\left(t_{0}=0\right)$ von Bertalanffy growth equation:

$$
L_{t}=L_{\max }\left(1-e^{k t}\right)
$$

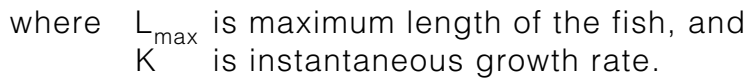

The weight of the fish (W) at age (t) was determined using a length-weight relationship:

$$
W_{t}=a L_{t}^{b}
$$

where $a$ is $L-W$ conversion coefficient, and $b$ is $L-W$ growth factor.

The percent maturity $\left(P_{t}\right)$ of individuals in the cohort-at-age was expressed using a LCDF:

$$
P_{t}=\left(1+e^{(-\alpha 1 \times(t-\beta 1))}\right)^{-1}
$$

where $\alpha 1$ is steepness of the curve, and $\beta 1$ is age at $50 \%$ maturity.

The numbers of individuals $\left(\mathrm{N}_{\mathrm{t}}\right)$ remaining in the fished cohort at age $(\mathrm{t})$ was determined using an instantaneous exponential decay function incremented at the time step of 0.1 years:

$$
N_{t}=N_{(t-1)} \times e^{-0.1 M}
$$

where $\mathrm{M}$ is instantaneous natural mortality, and $\mathrm{N}_{\mathrm{O}}$ is 1000
The biomass $\left(\mathrm{B}_{\mathrm{t}}\right)$ of the individuals remaining in the unfished cohort at age (t) was calculated:

$$
B_{t}=N_{t} \times W_{t}
$$

and the unfished spawning stock biomass (UFSSBt) of the individuals remaining in the cohort-at-age (t) was determined:

$$
\mathrm{UFSSB}_{\mathrm{t}}=\mathrm{P}_{\mathrm{t}} \times \mathrm{B}_{\mathrm{t}}
$$

Based on the previously reviewed gear selection literature, trawls and hooks were assumed to possess qualitatively similar size selection characteristics, which could be represented by LCDF of individual fish length $\left(\mathrm{PL}_{\mathrm{L}}\right)$ :

$$
\left.\left.P L_{L}=\left(1+e^{(-\alpha 2 \times(L-L} 50\right)\right)\right)^{-1}
$$

where $\alpha 2$ is steepness of the curve, and

$$
L_{50} \text { is length at } 50 \% \text { selection. }
$$

Gillnets and traps were assumed to possess qualitatively similar size-selection characteristics which could be represented by a truncated, scaled NPDF of individual fish length $\left(P N_{L}\right)$ :

$$
P N_{L}=e-\left(L-L_{o p t}\right)^{2} /(2 \times S D)
$$

where SD is standard deviation, and $L_{\text {opt }}$ is length of maximum selection.

Applying length-specific susceptibility to fishing $\left(P N_{L}\right.$ or $\left.P L_{L}\right)$ at a specified level of fishing mortality $(F)$ and including natural mortality $(M)$, the number of individuals remaining in the fished cohort $\left(\mathrm{NF}_{\mathrm{t}}\right)$ at each time step (t) was calculated as:

$$
N F_{t}=N F_{(t-1)} \times e^{-\left(\left(P N_{L} \text { or } P L_{L}\right)(F)+M\right)(0.1)}
$$

Thus, the yield of the fished cohort $(Y)$ from each time-step was:

$$
\begin{aligned}
& Y_{t}=\left(P N_{L} \operatorname{or}_{P L}(F)\right) /\left(\left(P N_{L} \text { or } P L_{L}\right)(F)+M\right) \times \\
& \left(N F_{(t-1)}-N F_{t}\right) \times W_{t}
\end{aligned}
$$

and the spawning stock biomass of the fished cohort $\left(\mathrm{SSB}_{\mathrm{t}}\right)$ at each time step is simply:

$$
\operatorname{SSB}_{t}=\left(N F_{t}\right) \times\left(W_{t}\right) \times\left(P_{t}\right)
$$

Given these equations and specific values of $L_{\text {max }}, K, a, b, \alpha 1, \beta 1$, and $M$, the total biomass and spawning stock biomass of the unfished cohort were determined. With the specification of fishing conditions ( $F, \alpha 2, L_{50}, S D$, and $L_{\text {opt }}$ ), total yield and spawning stock biomass of the fished cohort were determined. By evaluating a wide range of $L_{50}$, $L_{\text {opt }}$ and $F$ values, the resulting matrix of data, expressed as a percentage of the maximum value, was contoured to produce isopleth diagrams of yield-per-recruit (YPR) and spawning stock biomass-per-recruit (SPR). 
The effect of the shape of the selectivity function on YPR and SPR was evaluated by specifying a range of steepness and standard deviations for the LCDF and NPDF while holding other factors constant.

An estimate of yield-per-recruit-per-unit-effort (YPRPUE) was determined for a specified $L_{\text {opt }} / L_{50}$ and fishing mortality rate $(F)$, assuming $F$ was proportional to effort.

$$
\text { YPRPUE }=\text { YPR/F }
$$

\section{Results}

The specifications for the idealized groundfish used in this analysis were: $L_{\max }=100 \mathrm{~cm}, \mathrm{~K}=0.2$, $a=0.00001, b=3, \alpha 1=1, \beta 1=3$, and $M=0.2$. Based on these values, the characteristics of the individuals and the cohort of idealized groundfish are shown in Fig. 1 and 2. An individual idealized groundfish reaches an asympotic maximum length and weight of $100 \mathrm{~cm}$ and $10 \mathrm{~kg}$, respectively. Maturation was assumed to occur rapidly, with $50 \%$ of the cohort being mature at an age of 3 years and a length of about $45 \mathrm{~cm}$. Based on an initial cohort of 1000 , the number of individuals in the unfished cohort reduced to about $5 \%$ of the initial number by the age of 16 years, although the model was extended to an age of 30 years when only a single fish remained. Biomass of the cohort peaked at an age of 6.3 years and at an individual fish length of $75 \mathrm{~cm}$.
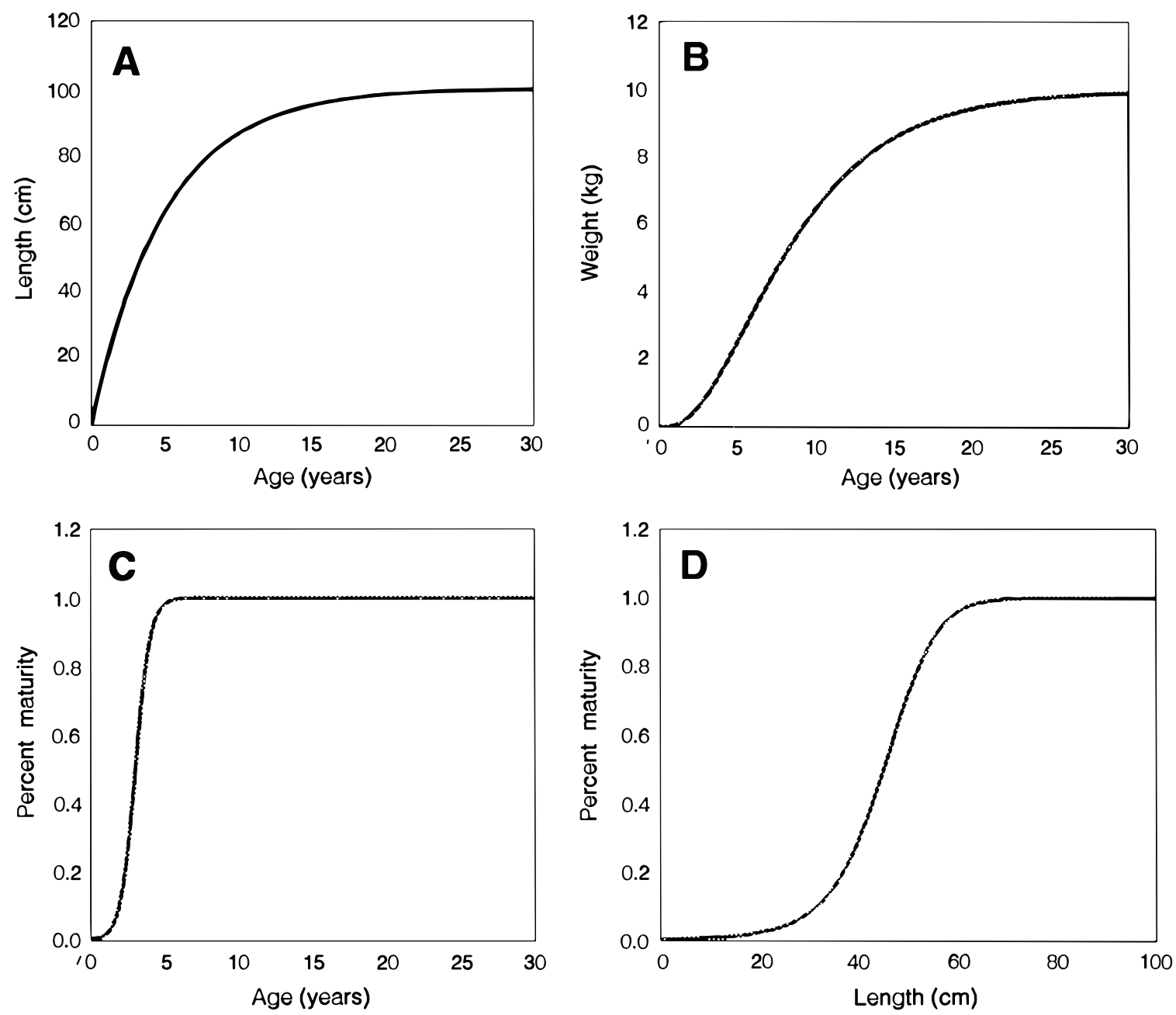

Fig. 1. Functional characteristics of a unfished cohort of an idealized groundfish.
(A) Length vs Age
(B) Weight vs Age
(C) Percent Maturity vs Age
(D) Percent Maturity vs Length 

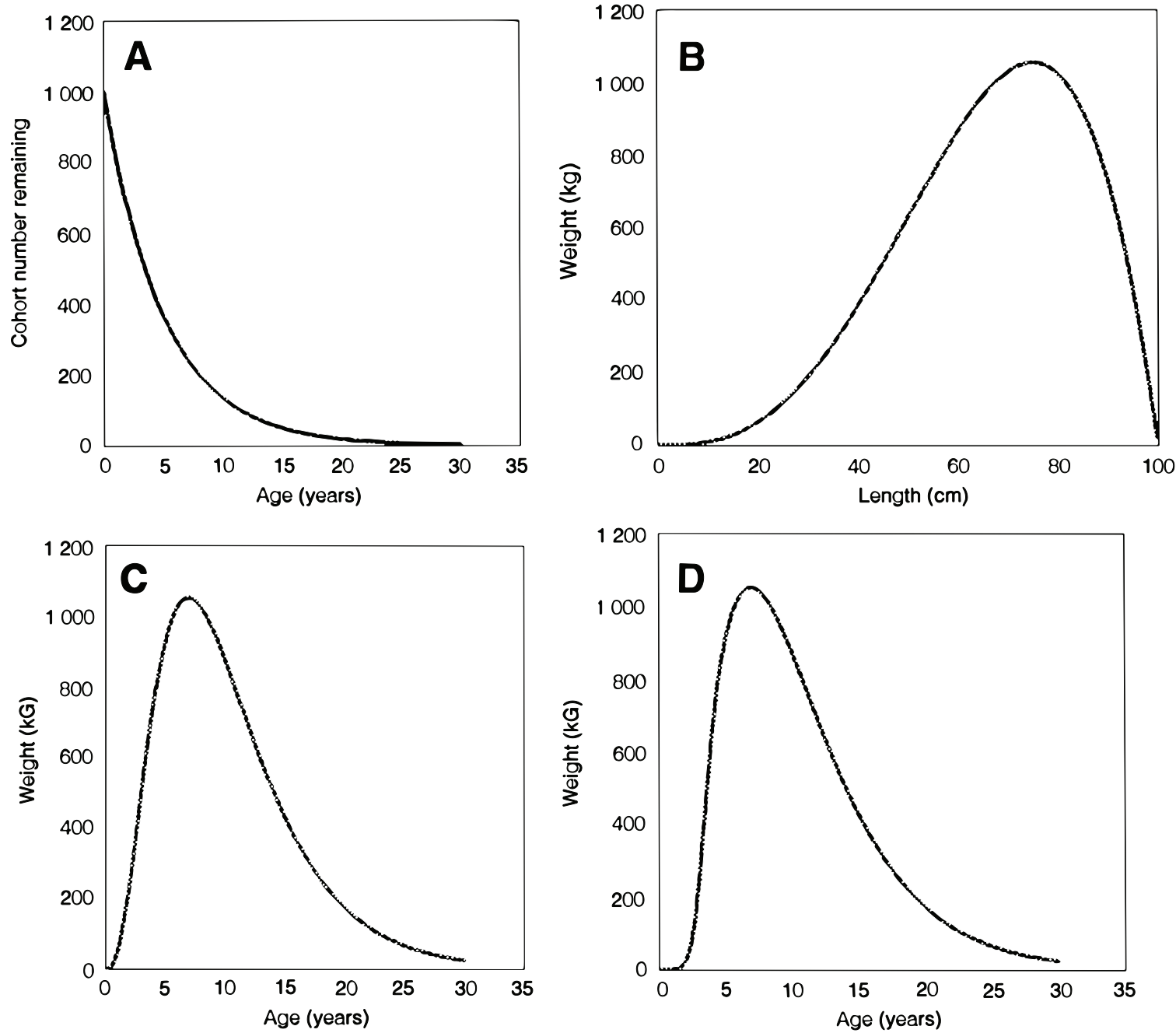

Fig. 2. Functional characteristics of a unfished cohort of an idealized groundfish.
(A) Numbers vs Age
(B) Biomass vs Length
(C) Biomass vs Age
(D) Spawning Biomass vs Age

The LCDF and NPDF for size selection are shown in Fig. 3A and $3 B$, respectively. The $L_{50}$ for the LCDF ranged from 50 to $100 \mathrm{~cm}$, and a representative steepness of 0.33 was specified. The $L_{\text {opt }}$ for the NPDF also ranged from 50 to $100 \mathrm{~cm}$, and a representative standard deviation of 5 was specified.

The YPR portion model was validated by comparing the results of the yield calculation from the spreadsheet program to the result of the analytical solution of the Beverton-Holt yield equations that assumes knife edge selection at a specific age of recruitment to the fishery (Saila et al., 1988). Identical specifications were input to each model, except that for the spreadsheet model the steepness of the logistic distribution selection curve was set so as to approximate knife-edge selection. Yield-per-recruit was determined for whole unit values of $\mathrm{F}$ from 0 to 7 . The resulting curves of YPR versus fishing mortality were identical in shape but offset a small amount (by less than $4 \%)$. This error was attributed to the difference between the analytic solution to the equation (the 

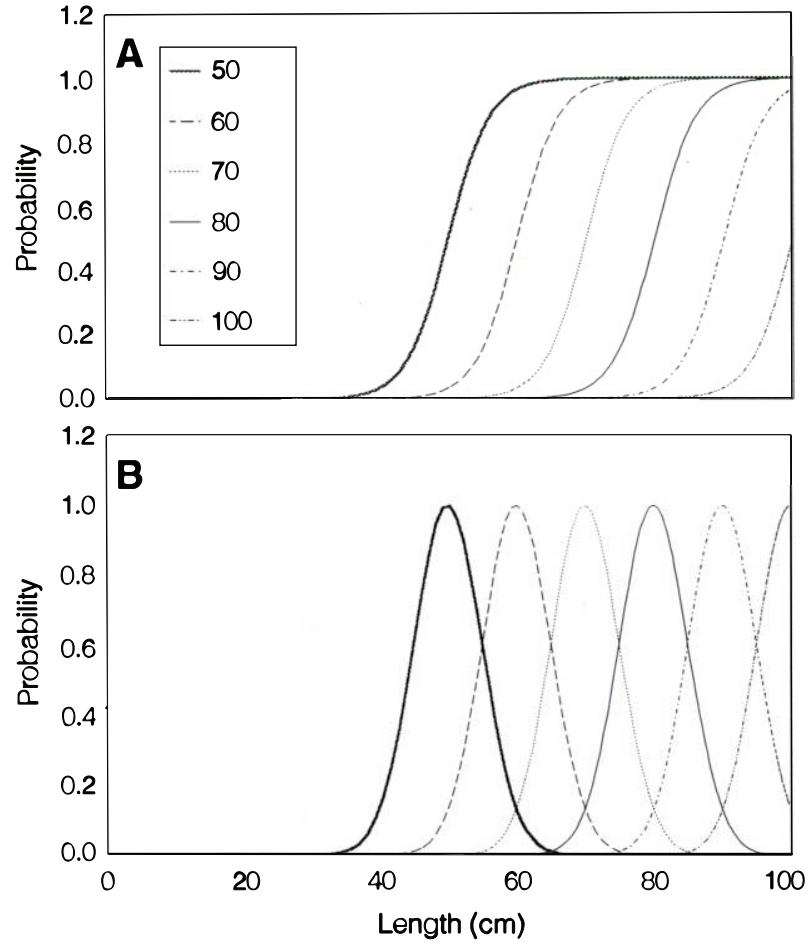

Fig. 3. Selection characteristics of harvesting gears used on the cohort of idealized groundfish.

(A) Logistic cumulative distribution function (LCDF) selectivity curves.

(B) Normal probability density function (NPDF) selectivity curves.

higher values) and the discrete-time model (the lower values). Increasing the time-step from 0.1 to 1.0 years exacerbated the error considerably.

The spreadsheet program was then run for a range of $F$ values from 0.5 to 4.0 at 0.5 intervals, calculating YPR and SPR values for both types of selection functions at each of the six $L_{50}$ and $L_{o p t}$ values. The resulting isopleth diagrams for YPR and SPR are shown in Fig. 4 and 5 for the LCPD and NPDF, respectively.

Evaluating the isopleth diagrams for the LCDF, it is clear that maximum YPR will be realized at an $L_{50}$ of $80 \mathrm{~cm}$ and at $F$ values of 3.0 and greater. Operating the fishery in this range will provide a relative SPR of $35 \%$ at $F=3.0$, decreasing to $26 \%$ at $F=4.0$.

Evaluating the isopleth diagrams of the NPDF, it is clear again that maximum YPR will be realized at $a L_{\text {opt }}$ of $80 \mathrm{~cm}$ and at $F$ values of 2.0 and greater.
Operating the fishery in this range will provide a spawning stock biomass of $30 \%$ at $F=2.0$, decreasing to $26 \%$ at $F=4.0$.

The effect of the shape of the selection curve on the YPR and SPR was evaluated at an $L_{50}$ or $L_{\text {opt }}$ of $80 \mathrm{~cm}$ and an $F$ value of 3.0. Steepness values ranging from 0.13 to 2.00 were specified for the LCDF (Fig. 6). The steepness of the selection curve had virtually no effect on the YPR, but clearly affected the SPR. Lower values for the steepness parameter resulted in a $50 \%$ reduction of the SPR. Standard deviation values ranging from 2 to 10 were specified for the NPDF (Fig. 7). The standard deviation of the selection curve again had no effect on the YPR, but again affected the SPR. Higher values for the standard deviation resulted in a $50 \%$ reduction in the SPR.

YPR and YPRPUE at a specified $L_{50}$ or $L_{\text {opt }}$ of $80 \mathrm{~cm}$ was evaluated over a range of $F$ values for both selectivity functions (Fig. 8). While there is little difference in the shape or values of the curves, it is evident that YPRPUE is maximized at a an $F$ value of about 0.5 and decreases markedly from that point on. In contrast, YPR is maximized at $F$ values of 3 and greater, but note that approximately 80 and $90 \%$ of the maximum potential YPR is realized at $F$ values of 0.5 and 1.0 , respectively.

\section{Discussions and Conclusions}

The general objective of this research was to develop a generalized model of YPR and SPR that incorporates the size selectivity characteristics of the principal harvesting gear types.

The selection characteristics of trawls and hooks have been represented by a LCDF of varying $L_{50}$ and steepness values, and the selection characteristics of gillnets and traps have been represented by a NPDF of varying $L_{\text {opt }}$ and standard deviation values. The isopleth diagrams for yield for both the LCDF and NPDF selectivity indicate a maximum YPR of approximately $1.075 \mathrm{~kg}$ at $F$ values of 3.0 and greater, and $L_{50}$ or $L_{\text {opt }}$ values of $80 \mathrm{~cm}$. At these relatively high levels of $F$ (3.0 and greater), the specific shape of the distribution function for the size selection has no effect on the YPR, but significantly affects the SPR. The sharper the selection process, the greater the SPR available for production of future cohorts.

In contrast, YPRPUE is maximized at an $F$ value of about 0.5, given the age at entry or length of susceptibility is set at the age or length of maximum biomass for the unfished cohort. 

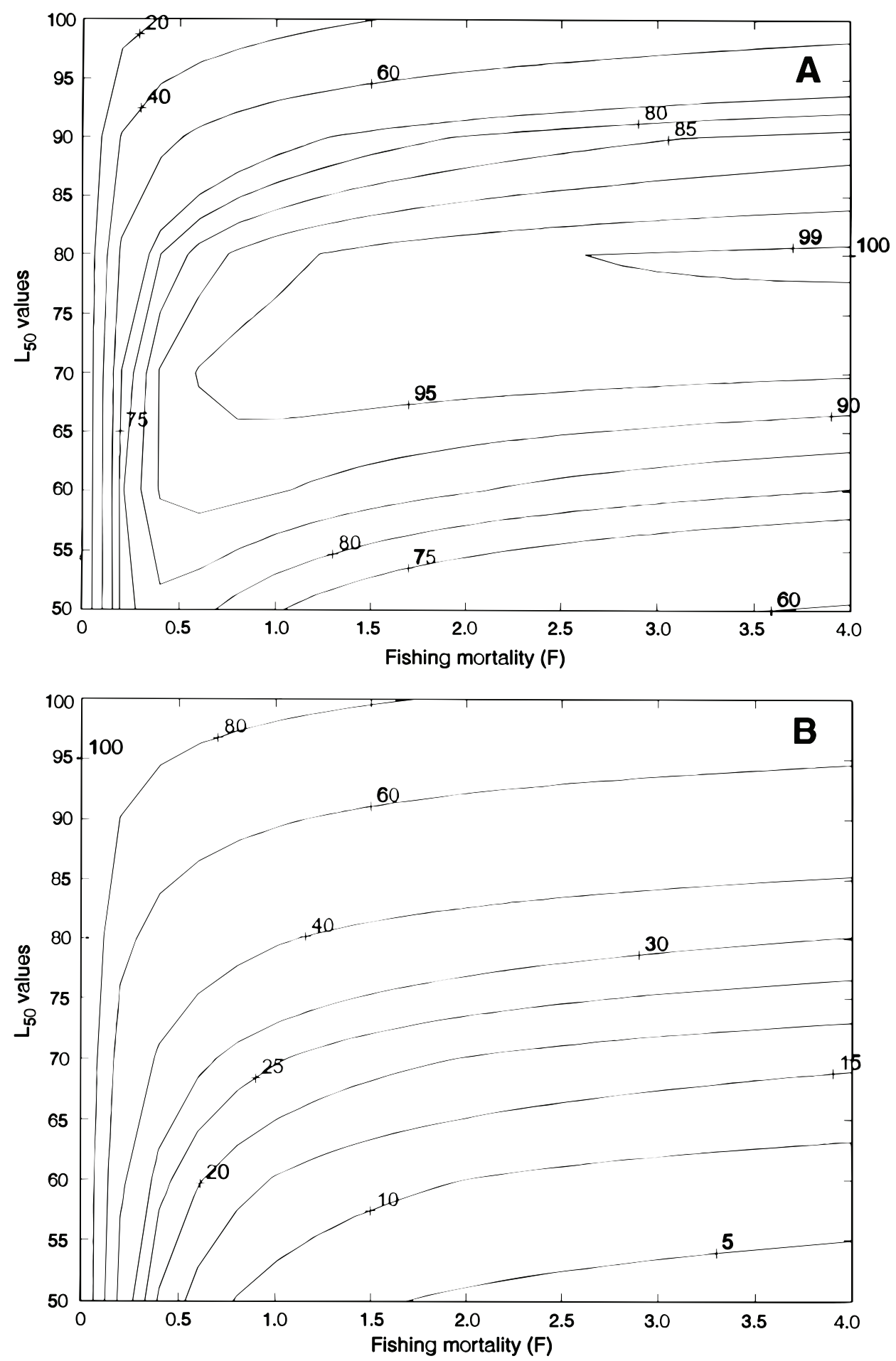

Fig. 4. Isopleth diagrams express as a percentage of maximum for: (A) yield-per-recruit (YPR), and (B) spawning stock biomass-per-recruit (SPR) for size selection based on a logistic distribution function (LCDF). 

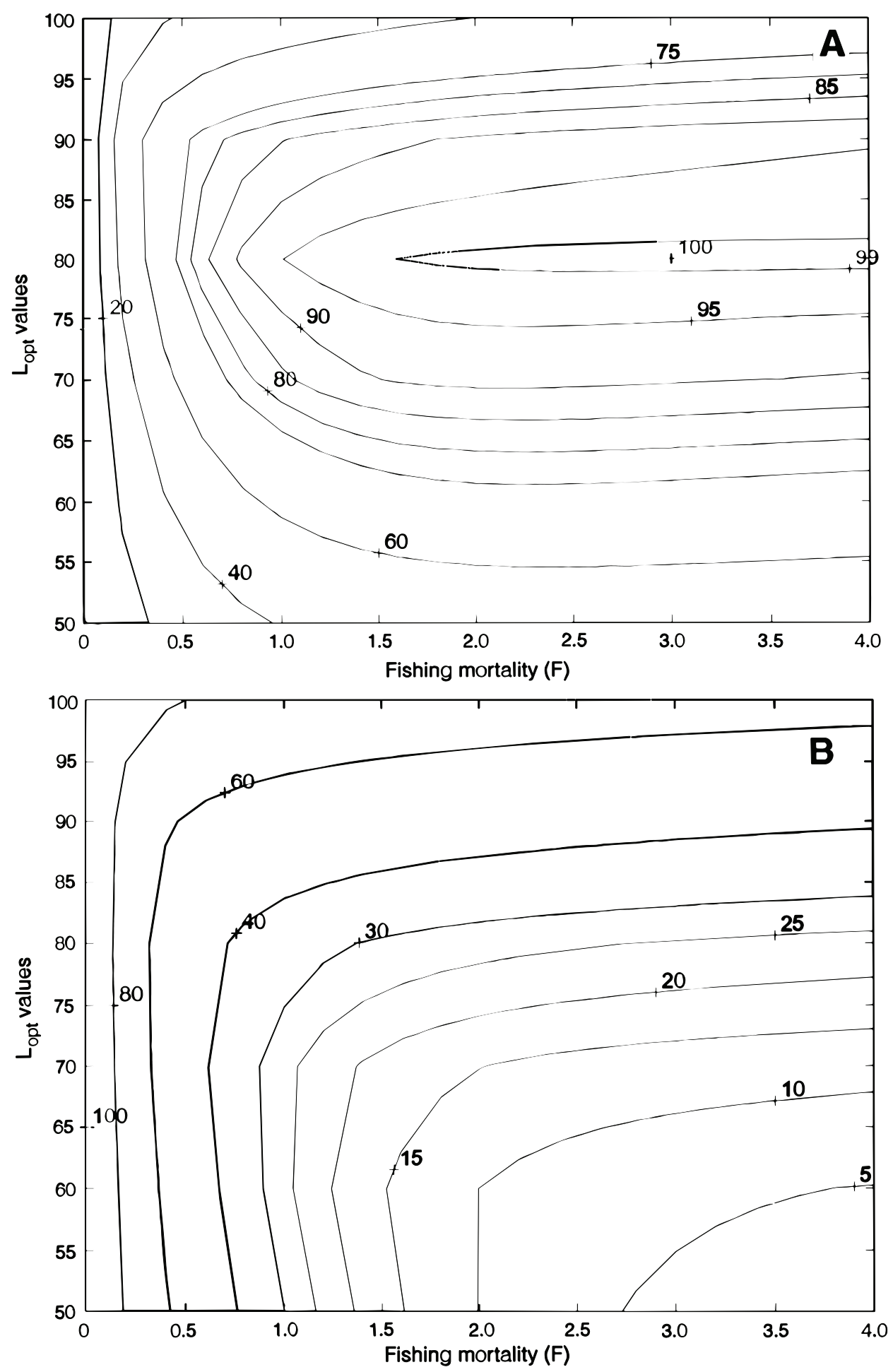

Fig. 5. Isopleth diagrams expressed as a percentage of maximum for: (A) yield-per-recruit (YPR), and (B) spawning stock biomass-per-recruit (SPR) for size selection based on a normal probability density function (NPDF). 

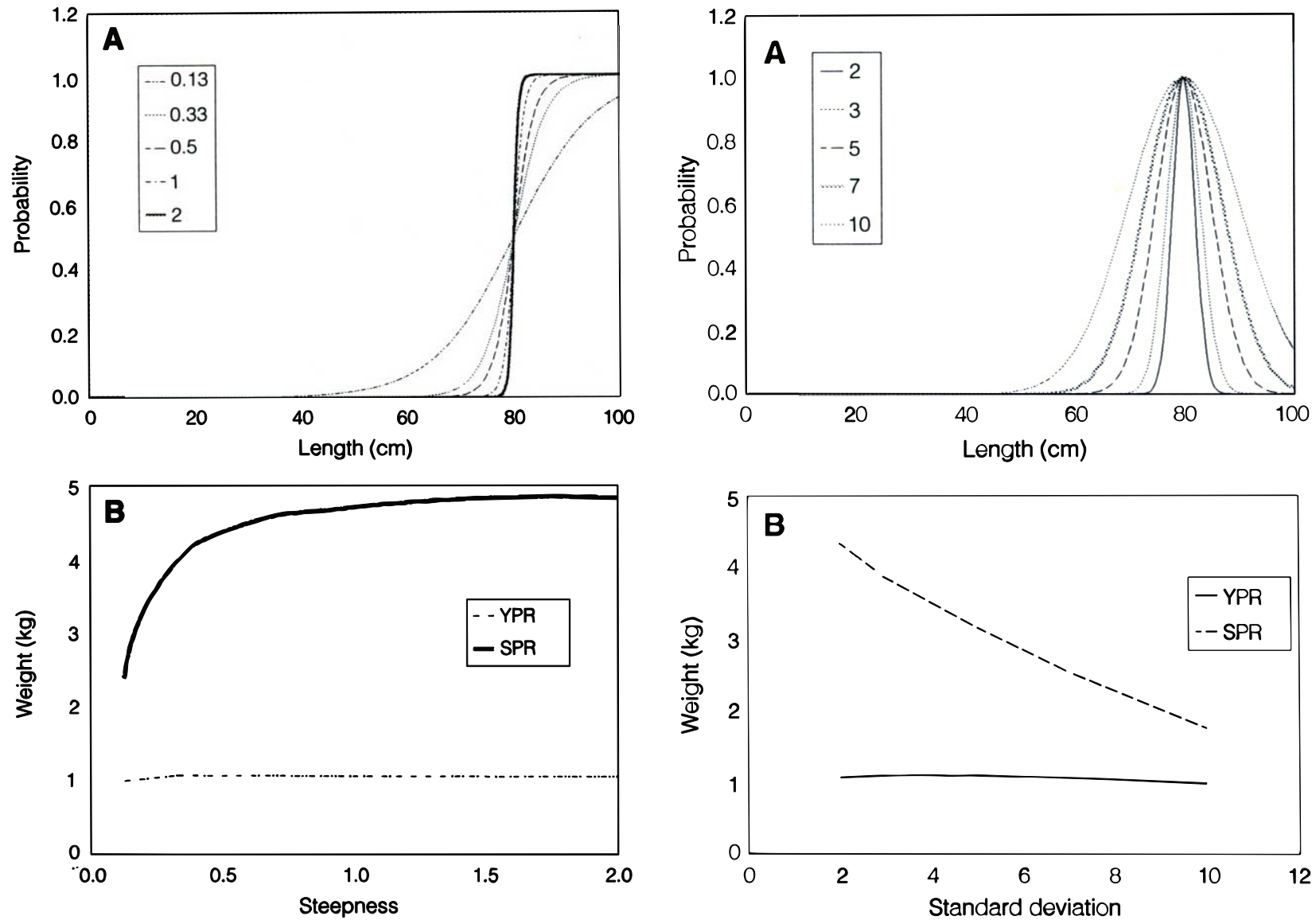

Fig. 6. Effect of the steepness of the logistic cumulative distribution function (NPDF) on: (A) size selective curve, and (B) yield-per-recruit (YPR) and spawning biomass-per-recruit (SPR), at $L_{50}=80$ $\mathrm{cm}$ and $\mathrm{F}=3.0$ for the cohort of an idealized groundfish.

These results present a dilemma for the fishery resource manager: maximize cohort yield at $F$ values of 2 and greater, with a minimum $65 \%$ reduction in YPRPUE, or maximize YPRPUE with a $25 \%$ reduction in YPR. However, with compromise, $85 \%$ of the maximum YPR can be realized with only a $20 \%$ reduction of YPRPUE at an $F$ level of 0.75 .

Ongoing research using this model includes applications to specific groundfish species of Northwest Atlantic Ocean, using stock specific

Fig. 7. Effect of the standard deviation of the normal probability density function (NPDF) on: (A) size selectivity curve, and (B) yield-per-recruit (YPR) and spawning biomass-per-recruit (SPR), at $\mathrm{L}_{\mathrm{opt}}$ $=80 \mathrm{~cm}$ and $\mathrm{F}=3.0$ for the cohort of an idealized groundfish.

biological parameters, and demonstrated gear selectivity characteristics.

\section{Acknowledgements}

Financial support for this project was provided by Rhode Island Sea Grant and the University of Rhode Island College of Resource Development. This publication is number 2907 of the Rhode Island Agricultural Experiment Station. The authors appreciate the critical comments of Grant C. Thompson and an anonymous reviewer. 

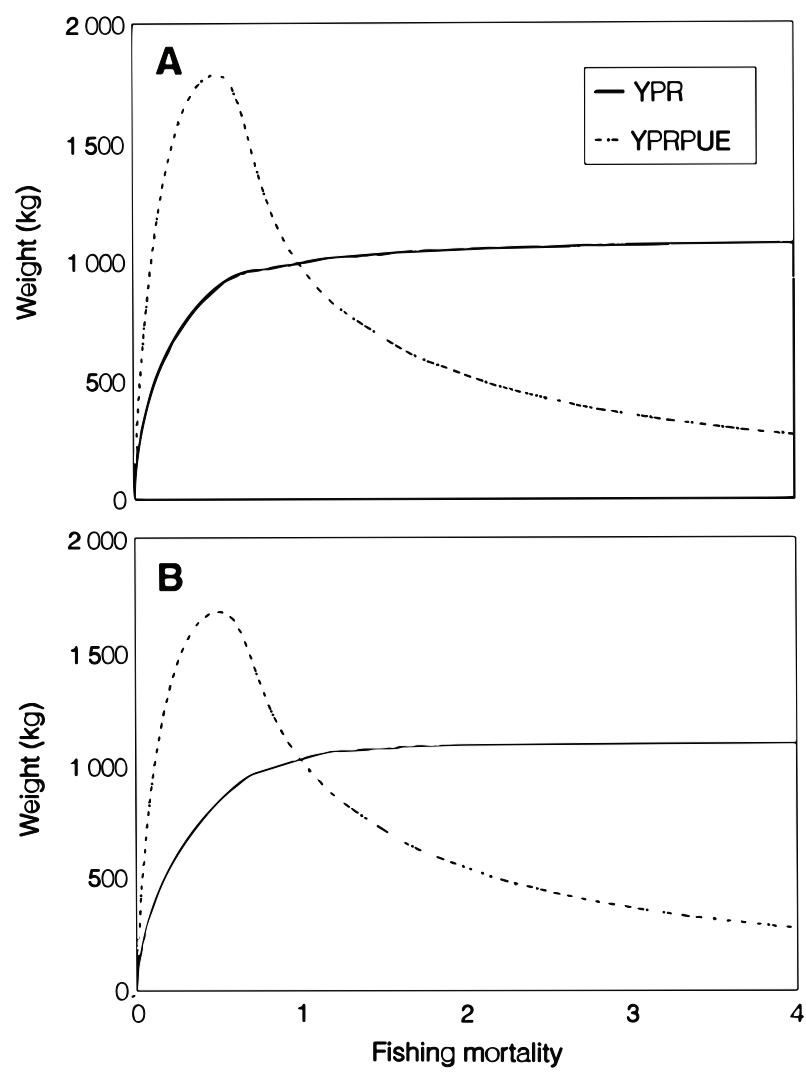

Fig. 8. Yield-per-recruit-per-unit-effort (YPRPUE) and yield-per-recruit (YPR) as a function of fishing mortality for: (A) logistic cumulative distribution function (LCDF) selectivity, and (B) normal probability density function (NPDF) selectivity, for an $\mathrm{L}_{50}$ or $\mathrm{L}_{\text {opt }}$ of $80 \mathrm{~cm}$.

\section{References}

ANON. 1963. The selectivity of fishing gear. ICNAF Spec. Publ., 5: 225 p.

BARANOV, F. I. 1918. On the question of the biological basis of fisheries. Nauch. isledov. iktiol. Inst. Ixv, Vol. 1, No. 1, p. 81-128.

BERTRAND, J. 1988. Selectivity of hooks in the handline fishery of the Saya de Malha Banks (Indian Ocean). Fish. Res., 6: 249-255.

BEVERTON, R. J., and. S. J. HOLT. 1957. On the dynamics of exploited fish populations. Fish. Invest. Minist. Agric. Fish. Food Series II, 19: 533 p.

BOHNSACK, J. A., D. L. SUTHERLAND, D. E. HARPER, D. B. MCCLELLAN, M. W. HULSBECK, and C. M. HOLT. 1989. The effects of fish trap mesh size on reef fish catch off southeastern Florida. Mar. Fish. Rev., 51(2): 36-46.

BORGSTROM, R. 1989. Direct estimation of gill-net selectivity for roach (Rutilus rutilus (L.)) in a small lake. Fish. Res., 7: 289-298.

CLARK, J. R. 1960. Report on selectivity of fishing gear. In: Fishing effort, and effect of fishing on resources and the selectivity of fishing gear. ICNAF Spec. Publ., 2: $27-36$
1963. Size selection of fish by otter trawls, results of recent experiments in the Northwest Atlantic. ICNAF Spec. Publ., 5: 24-96.

DEALTERIS, J. T., and D. M. REIFSTECK. 1993. Escapement and survival of fish from codend of a demersal trawl. ICES Mar. Sci. Symp., 196: 128-131.

GULLAND, J. A. 1969. Manual of methods for fish stock assessment. Part 1. Fish population analysis. FAO Man. Fish. Sci., 4: 154 p.

1983. Fish stock assessment. John Wilsey and Sons, N.Y., 223 p.

HAMLEY, J. M. 1975. Review of gillnet selectivity. J. Fish. Res. Board. Can., 32: 1943-1969.

HAMLEY, J. M., and H. A. REGIER. 1973. Direct estimates of gillnet selectivity to walleye (Stizostedion vitreum vitreum). J. Fish. Res. Board Can., p. 817-830.

HOLT, S. J. 1963. A method for determining gear selectivity and its applications. ICNAF Spec. Publ., 5: 106-115.

LAZER, N., and J. DEALTERIS. 1993. Gear selectivity/ technical interaction in a mixed species fishery. URI Tech. Rpt. 93-2, 23 p.

MCCRAKEN, F. D. 1963. Selection by codend meshes and hooks on cod, haddock, flatfish and redfish. In: The Selectivity of Fishing Gear. ICNAF Spec. Publ., 5: 131-155.

OTWAY, N. M., and J. A. CRAIG. 1993. Effects of hook size on the catches of undersized snapper Pagrus auralius. Marine Ecology Progress Series, Vol. 93: 915.

PAULEY, D. 1984. Fish population dynamics in tropical waters: a manual for use with programmable calculators. ICLARM, Philippines, $324 \mathrm{p}$.

POPE, J. A., A. R. MARGETTS, J. M. HAMLEY, and AKYUZ. 1975. Manual of methods for fish stock assessment. Part III. Selectivity of fishing gear. FAO Fish. Tech. Pap., No. 41(Rev. 1): 1-46.

RALSTON, S. 1982. Influence of hook size in the Hawaiian deep-sea handline fishery. Can. J. Fish. Aquat. Sci., 39: 1297-1302.

1990. Size selection of snappers (Lutjanidae) by hook and line gear. Can. J. Fish. Aquat. Sci., 47: 696700.

REGIER, H. A., and D. S. ROBSON. 1966. Selectivity of gill nets, especially to lake whitefish. J. Fish. Res. Board Can., 23: 423-454.

RICKER, W. E. 1975. Computation and interpretation of biological statistics of fish populations. Bulletin 191, Fish. Res. Board Can., 382 p.

SÆETERSDAL, G. 1963. Selectivity of longlines. In: The Selectivity of Fishing Gear. ICNAF Spec. Publ., 5: 89192.

SAILA, S. B., C. W. RECKSIEK, and M. H. PRAGER. 1988. Basic fishery science programs. Elsevicia, N.Y., $230 \mathrm{p}$.

SMOLOWITZ, R. N. 1983. Mesh size and the New England ground fishery - applications and implications. NOAA Tech. Rpt. NMFS. SSRF-776, pp. 121.

SPARRE, P., E. URSIN, and S. VENEMA. 1989. Introduction to tropical fish stock assessment. Part I. Manual. FAO Fish. Tech. Paper, 306/1, 337 p.

STEVENSON, D. K., and P. STUART-SHARKEY. 1980. Performance of wire fish trap on the western coast of Puerto Rico. Proc. Gulf Cont. Fish. Inst., 32: 173-193.

WARD, J. 1988. Mesh size selection in Antillian arrowhead fish traps. In: Tropical Fisheries Biology. FAO Fish. Report, 389: 455-467. 